\title{
Impact of management style of managers on amount of parent participation in schools issues in the saveh city, Iran
}

\author{
${ }^{1}$ Ali Rezaei, ${ }^{2}$ Davoud Hoseinzadeh, ${ }^{3}$ Zeinolabedin amini sabegh, \\ ${ }^{4}$ Reza Shafizadeh \\ ${ }^{1}$ Student of Education management, Islamic Azad University, Saveh Branch, Saveh,Iran \\ 2,3,4Departmen ${ }^{t}$ of Human Science, Islamic Azad University, ,Saveh Branch, Saveh,Iran
}

\begin{abstract}
This study aims to investigate the effect of the management style of the managers on the level of the parents' participation in the schools affairs. This study was conducted in 2013 and its statistical population included 312 subjects among all the teachers and parents of the public high schools of Iranian Saveh City (including 156 teachers and 156 parents who were the members of the Trainers-Parents Community). Among the mentioned population 144 subjects were selected as the research sample by usingCochranformula and sampling method of stratified random sampling method. In this process, 8 teacher and 8 parents were selected from each school in random. The data collection was conducted using two questionnaires: standard questionnaire of management styles, and a research-made questionnaire for the parents' participation. To analyze the data we relied on structural equation modeling method using LISREL 8.8 and Smart PLS 2 softwares in modeling and structural parts. In the modeling part we investigated the technical characteristics of the questionnaire and corrected the questionnaire as needed; and in the structural part, we used the structural coefficients of the model to test the hypotheses of the research. The results showed that the management style of the managers has a positive significant effect on the parents' participation in the school affairs and on the reinforcement of the relationship between the home and the school. This is while the management style of the managers has no significant effect on the educational affairs, supporting affairs, and the reinforcement of the relationship between the school and the society.
\end{abstract}

Keywords: Collaborative, Magisterial, Management Styles, Parents participation, Parents-Teachers Community,

\section{Introduction}

Considering the vital role of the parents in the education of their children, some financial, educational, supporting, and training issues of the educational institutions have faced the school managers with some specific problems that can be resolved only by the participation of the parents in decision-makings of the school. Today's managers are no longer the role-models of the people in all areas because nowadays, any society needs the participation of different groups and practically it is impossible for a single person to own all prominent and good possible characteristics (Stern, 2003). Nowadays, the management in local, national or organizational level benefits from the group participation more than ever because the number of the decisions and the complexity and relationship between the problems on one hand, and the necessity of coordination and planning with regard to the internal and external issues of the organization on the other hand forces the each school manager to make several decision simultaneously on different areas. This is why the traditional system of decision making in the organizations is in ruin (Smarkar and Cohon, 2007).

According to available literature, the interaction between the home and school is very important both in theoretical and practical levels. The participation and the interaction between the home and school specifically lead to the improvement of the educational situation of the students (Saki, 2009). The increase of the involvement and participation of the families is always one of the important ways of improving the quality of the schools. The studies show that the presence of the families in school has a considerable effect on the improvement of the students' attitude toward the education, their effective presence in the classrooms, and the attitude of the families toward the school. Moreover, such a participation will increase the satisfaction of the teachers, increases the needed resources of the school and leads to the reduction of the crimes and behavioral abnormalities among the students (Henderson and Berla, 1994; Hickman, 1996; Comer and Haynes, 1992; all quoted by Saki, 2009).

The available literature shows that currently the parents' participation in the school affairs is very limited and this point has faced the school with some problems in fulfilling their educational objectives. As a social system, the education supplies its needed resources from the society in order to run its mission. It is after such inputs that the educational system nurtures the students through some complicated procedures that require implementation of organizational structure, human resources, technology, etc. The result of this process is to 
grow the individuals that have been manipulated in some specific directions and have obtained some specific competences and qualifications (Feverstein, 2008).

\section{Theoretical framework and hypotheses of the research}

Considering the mentioned points, this study aims to find if there is a significant relationship between the management style of the school managers and the parents' participation in the affairs of the high schools. With regard to the literature review and the hypotheses, the theoretical framework of this research and its hypotheses are shown in Fig. 1.

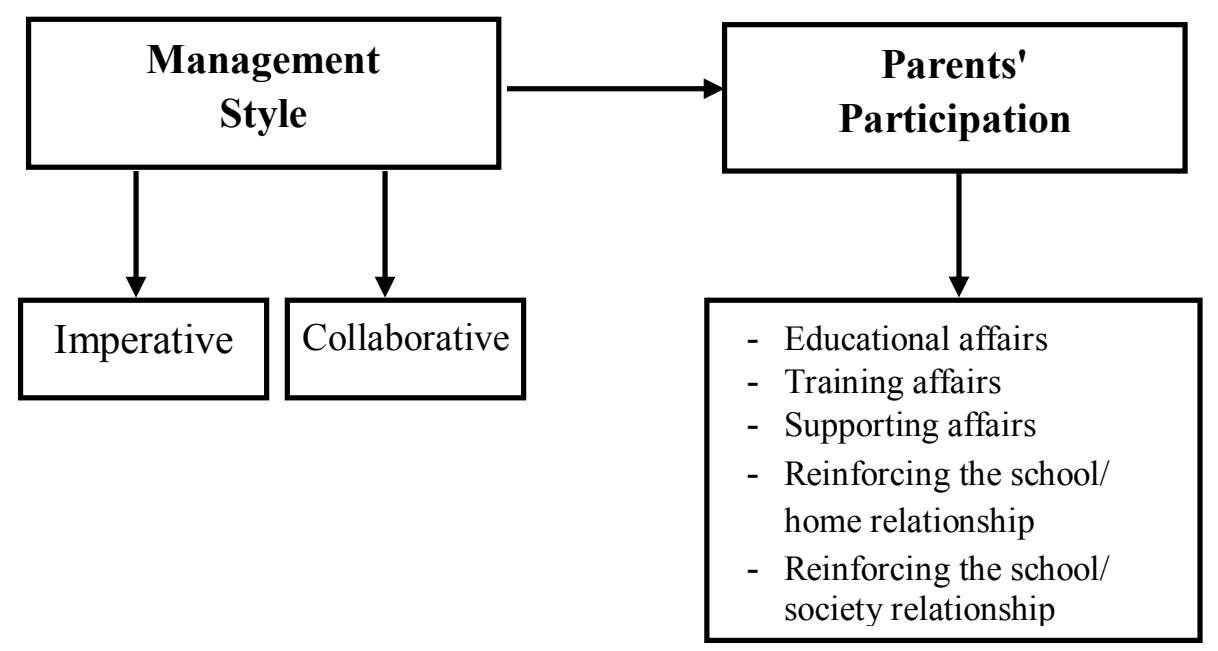

Fig. 1: Theoretical framework of the research

Main hypothesis: There is a relationship between the management style of the school managers and the level of parents' participation in the affairs of the high schools.

Subsidiary hypothesis 1: There is a relationship between the management style of the school managers and the level of parents' participation in the educational affairs of the high schools.

Subsidiary hypothesis 2: There is a relationship between the management style of the school managers and the level of parents' participation in the training affairs of the high schools.

Subsidiary hypothesis 3: There is a relationship between the management style of the school managers and the level of parents' participation in the supporting affairs of the high schools.

Subsidiary hypothesis 4: There is a relationship between the management style of the school managers and the level of parents' participation in reinforcing the school/home relationship in the high schools.

Subsidiary hypothesis 5: There is a relationship between the management style of the school managers and the level of parents' participation in reinforcing the school/society relationship in the high schools.

\section{Methodology of the research}

The methodology of this research is functional according to its objective, and it is a descriptivecorrelative survey according to its data collection method because it has polled the opinions of the involved subjects to confirm its hypotheses. Moreover, this is a quantitative research with regard to the type of its collected data. Accordingly, we planned and distributed a series of questionnaires in order to collect the opinions of the teachers and parents of the students of high schools in Saveh City, and the collected results were recorded. Since in this research the causal relationship was going to be studied, the methodology of the research is causal with regard to the relationship between the variables; and we have used the structural equation model to come to a comprehensive analysis of our conceptual model. Structural equation model is the best tool for the researches in which the observed variables have measuring errors, and the relationship between their variables is complex.Using this method we can study the indexes or observed variables on one hand and to assess the causal relationship between the latent variables and the explained value of variance (Hair and et al., 2010). Structural equation model encompasses two models: measurement model and the structural model; and the variables of the model are divided into two groups: latent variables and observed variables (Kline, et al, 2010). In this study, management styles and parents' participation are two main constructs each of which are based on the models of different authors as will be explained in the "measurement tool" section of this paper. Besides, each of these constructs are made of different dimensions, while each of these dimensions have been assessed by some items or questions (observed variables) as summarized in table 3. 


\section{Statistical population, sampling method, and sample size}

The population of the research contains all teachers and parents who are the members of the "Teachers and Parents Community" of the public high schools of Iranian Saveh City, which includes 312 subjects. Using stratifiedrandom sampling method and Cochran formula, we came to a sample of 144 subjects. In this regard, 8 teachers and 8 parents were selected from each of the 9 public high schools. To use the Cochran formula it is necessary to consider its assumptions. The assumptions of the Cochran formula include: $\mathrm{p}=\mathrm{q}=50 \%$ (on the basis of probabilistic method); $\mathrm{z}$ is the standard statistic for normal distribution that is equal to 1.96 at the confidence level of $95 \%$; $d$ is the maximum allowable error (equal to $5 \%$ for this research); and $\mathrm{N}$ is the number of the employees in all relevant companies. The sample size (n) is calculated according to equation 1 on the basis of the Cochran formula (Saraei, 2000):

$$
\mathrm{n}=\frac{\mathrm{z}^{2} \mathbf{p q N}}{\mathrm{Nd}^{2}+\mathrm{z}^{2} \mathbf{p q}}
$$

Thus using the equation 1 , considering the number of the statistical population $(\mathrm{n}=312), 144$ subjects were selected as the statistical sample. It is to be mentioned that 150 questionnaires were distributed among which the number of 144 questionnaire were completed and got back (response rate of $96 \%$ ).

Analyzing the data of the research

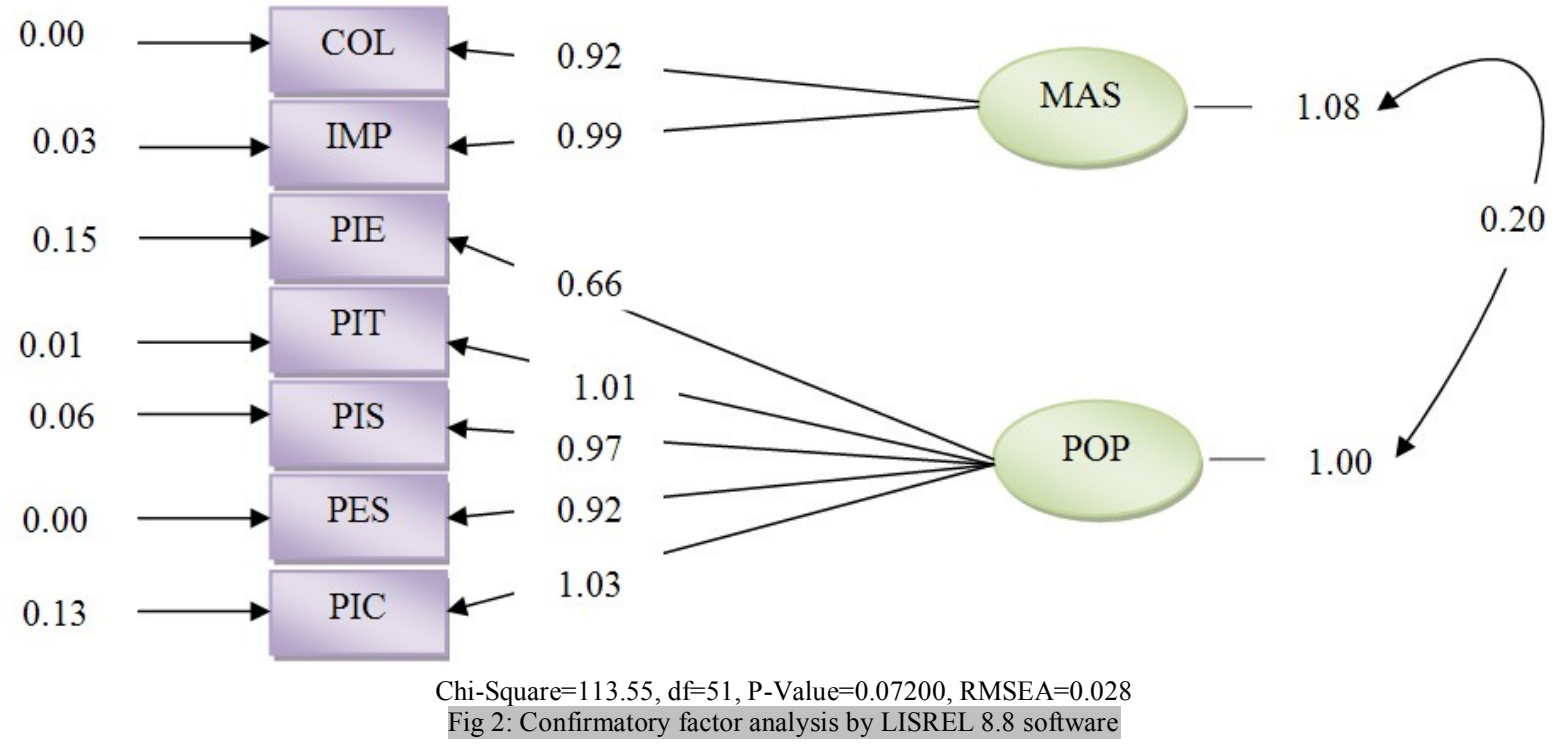

In the next step, we conducted confirmatory factor analysis using LISREL 8.8 in order to assess the used measuring model. According to Joreskog and Sorbom (1996), the fitness conditions of the model are as follow: the significant level obtaining from the chi-square test (p-value) is higher than 0.05 ; the ratio of chi-square to degree of freedom is less than 3; the value of the statistic of Root Mean Square Error of Approximation (RMSA) is less than 0.05; the value of comparative fitness index (CFI), general fitness index (GFI), adjusted general fitness index (AGFI), and non-norm fitness index (NNFI) are higher than 0.9. As it is shown in figure 3 (standardized coefficients), $\mathrm{p}$-value is equal to 0.072 ; RMSA is equal to 0.028 ; and the ratio of chi-square (113.55) to degree of freedom (51) is equal to 2.23 and thus it is less than 3. Moreover, other outputs of LISREL showed that the value of CFI is equal to 0.921 , the evaluated value of $\mathrm{Z}$ is higher than 1.96 ; and the values of GFI and AGFI are equal to 0.940 and 0.944 respectively. Thus the measurement models of the two main constructs of the research have an acceptable fitness. The causal relationship between the management styles and the parents' participation in the school affairs was assessed using the structural equation model and the Smart PLS 2 software. As shown in figure 3, the relationship between the two main constructs of the research is a direct significant relationship; accordingly, the management styles have a positive significant effect on the parents' participation in the school affairs (hypothesis 1). According to the output of Smart PLS 2 software, 47\% of the changes in the parents' participation in the school affairs are predicted by the management styles. The causal coefficients of the paths between the two main constructs of the research show the effect of the management styles on the parents' participation in the school affairs. 


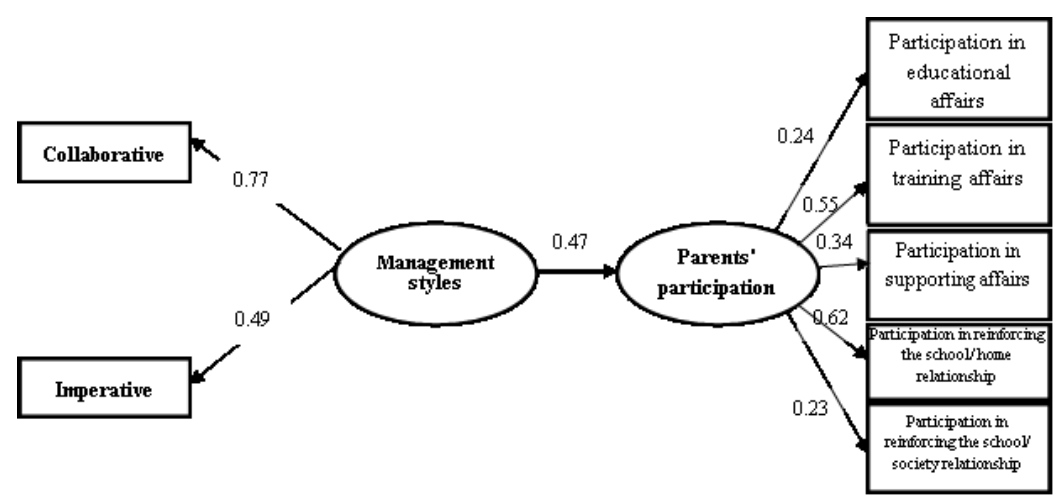

Fig. 3: Standard Coefficients

In order to confirm the hypotheses of the research we used the Bootstrapping command in Smart PLS software. The resulted output shows the t-values (Fig. 4). When the t-values stand in the interval between higher than +1.96 and less than -.196 , then the relevant parameter will be significant and accordingly, the hypotheses of the research are confirmed. As shown in figure 4, the t-coefficients between the two main constructs of the research (participation in training affairs and participation in reinforcing the relationship between the home and school) are higher than 1.96 and hence the corresponding hypotheses of the research.

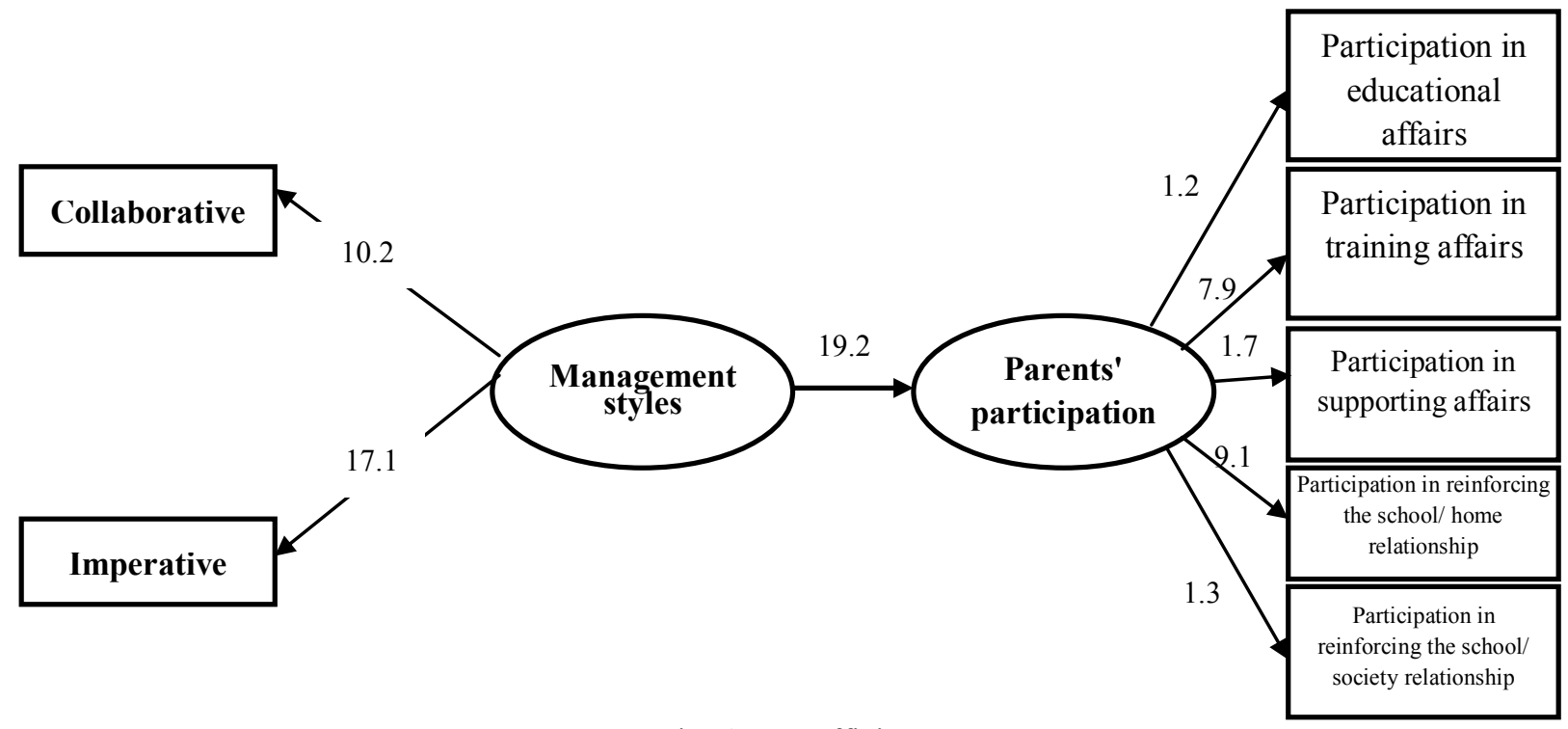

Fig. 4: t- coefficients

\section{Conclusion and discussion}

In this research we found that the schools in which the management style is collaborative can benefit from the higher rate of parents' participation. In contrast, the schools with imperative management will miss the parents' participation and its consequent potentials. Thus we can conclude that the management style explains $47 \%$ of the parents' participation.

The results of testing the first subsidiary hypothesis of the research showed that there is no significant relationship between the management style and the parents' participation in the educational affairs of the schools.

The parents typically think that the education is the task of the schools and all relevant issues of the education have to be undertaken by the school. With such an attitude, it is natural for the parents to be reluctant to participate in the educational affairs of the schools. As a matter of fact, some other factors such as the cultural poverty of the parents and their ignorance about the fate of their children along with their own busy works will reinforce their mentioned reluctance.

The results of testing the second subsidiary hypothesis of the research showed that there is a significant relationship between the management style and the parents' participation in the training affairs of the schools.

The significance of the relationship between the rates of the parents' participation in the training affairs of the schools can be explained as bellow: since the decision-making on the training issues is mainly done by the authorities of the school and it is not dependent on the regulations and provisions. Thus the educational 
managers do all needed coordination with the parents in order to conduct the training activities, and consequently the parents of the students willingly participate in the training affaire of the schools.

The results of testing the third subsidiary hypothesis showed that there is no significant relationship between the management style and the parents' participation in the supporting affairs of the schools.

Since most students of the public schools belong to the poor families and their families pay no fare for their study due to the free nature of the Iranian public schools, thus the families don't participate in the supporting affairs of the schools because of their poverty. This is why the management style has no significant effect on the parents' participation in the supporting issues of the schools.

The results of testing the fourth subsidiary hypothesis of the research showed that there is a significant relationship between the management style of the school managers and the parents' participation in reinforcing the home/school relationship.

The significance of the relationship between the management style of the school managers and the parents' participation in reinforcing the relationship between home and school we can state that some factors have played important role in reinforcing such a relationship, among which one can refer to the training courses for the parents that have been conducted by the schools, and the consultations that have been offered by the consultants, teachers and managers of the schools.

The results of testing the fifth subsidiary hypothesis showed that there is no significant relationship between the management style and the parents' participation in reinforcing the home/society relationship.

The main reasons of this insignificant relationship between the management style and the parents' participation in reinforcing the home/society relationship are the cultural poverty, lack of suitable social and economic situation, lack of knowledge about the components of reinforcing the home/society relationship, routine busy times of the parents, etc. These factors will lead to the reluctance of the parents to participate in the relevant affairs of the schools.

\section{References}

[1]. Saki, Reza, (2010), Leadership in the Learning-oriented Schools, Tehran: Tehran Organization of Education [in Persian]

[2]. Saraei, Hassan, (2010), An Introduction to Sampling in Research, Tehran: SAMT Publications [in Persian].

[3]. Sharifi, Alireza, (2007), Final Report of Comparative Study on the Parents' Participation in the School Affairs in Different Countries, Tehran: Parents and Teachers Research Center [in Persian].

[4]. Safi, Ahmad, (2009), Ways of Parents' Participation in the School Affairs from the School Managers' Point of View in 2001-2001, MSc. Dissertation, Educational Management Department, Islamic Azad University, Central Tehran Branch [in Persian].

[5]. Arabshahrab, Ali (2010), Relationship between the Management Styles (Collaborative and Imperative) and the Level of Using Parents' Participation in the High Schools of Varamin City, MSc. Dissertation, Islamic Azad University, Garmsar Branch [in Persian].

[6]. KazemiKordasiabi, Mitra, (2007), Relationship between the Human Skills of the Managers and the Level of Parents' Participation in the Secondary and High Schools of Babolsar City, MSc. Dissertation, Alzahra University [in Persian].

[7]. Mehralizadeh, Yadollah; Sepasi, Hossein; \&Yousefi, Mokhtar, (2006), "Comparative Study on the Position of the Teachers' Participation in the Process of Decision-making in the Public and Private High Schools", Journal of Psychology and Educational Sciences, Chamran University of Ahwaz, Winter 2006, No. 4, pp. 31-55 [in Persian].

[8]. Mirkamali, Seyyed Mohammad, (2009), Human Relationships in Schools, Tehran: Seytaroon Publications [in Persian].

[9]. Hasehmi, Saeid, (2008), Effective Factors on the Parents' Participation in Training Activities of the Schools in Behshahr city, MSc. Dissertation, Islamic Azad University, Sari Branch [in Persian].

[10]. Hersey, Paul; \& Blanchard, Kenneth, (2009), Management of Organizational Behavior, 10 ${ }^{\text {th }}$ Edition, Translated by Ali Alaqebandan, Tehran: Amir Kabir Publications [in Persian].

[11]. Bauch, P. and Goldring, E.(2009). parent-teacher-participation in the context of school governance. Journal of education, Vol3(4), pp:48-54.

[12]. Casellal, a. (2010). A study of site based decision-making based on the perspective of the participants. University of Pittsburg, M.A thesis of educational management.

[13]. Coots, J. (2004). Family resource and parent participation is schooling activities for their children with developmental delays. Journal of special education and training, Vol 31(3), pp:112-122.

[14]. Feverstein, A. (2008). School characteristics and parent involvement influences on

[15]. Hulland, J. (1999). 'Use of partial least squares (PLS) in strategicmanagement research: A review of four recent studies.Strategic Management Journal, 20(2), Pp:195-204.

[16]. Joreskog, K. \&Sorbom, D. (1996). Structural Equation Modeling with the SIMPLIS Command Language. Chicago, IL: Scientific Software International, Inc.

[17]. participation in children's school. journal of education research, Vol 19(7),pp:32-39.

[18]. Smrekar, C., and Cohon, C. (2007). The voices of parents: rethinking. The intersectional of family and school. Peabody journal of education $76,2,75-92$

[19]. Stern, J. (2003). Involving parents, London, ContinumGestwicki, Carol (2000) Home, School and community relations, New york. 